\title{
KESESUAIAN LAHAN BUDIDAYA RUMPUT LAUT EUCHEUMA COTTONII DI PERAIRAN TARAKAN DENGAN FAKTOR PEMBATAS VARIABILITAS ENSO DAN MUSIM
}

\author{
Evie Avianti ${ }^{122}$, Nani Hendiarti ${ }^{2)}$ \& Tuty Handayani1) \\ 1)Magister IImu Kelautan, Fakultas MIPA, Universitas Indonesia \\ 2) Pusat Teknologi Inventarisasi Sumberdaya Alam - Badan Pengkajian dan Penerapan Teknologi \\ Diterima tanggal: 20 Januari 2015; Diterima setelah perbaikan: 9 April 2015; Disetujui terbit tanggal 12 Juni 2015
}

\begin{abstract}
ABSTRAK
Satelit inderaja oseanografi Aqua MODIS dan altimetri digunakan untuk mempelajari perubahan parameter lingkungan perairan Tarakan (suhu, klorofil-a, arus permukaan) terhadap variabilitas ENSO dan musim, agar diperoleh pemahaman dinamika oseanografi selama perioda EI Nino (Desember 2008, Januari-Februari 2009), La Nina (September-Oktober-November 2010), dan Normal ((Mei-Juni-Juli 2012), Musim Barat (Desember, Januari, Februari selama 2008, 2009, 2010, 2012), dan Timur (Juni, Juli Agustus selama 2009, 2010, 2012). Analisis kesesuaian lahan budidaya Eucheuma cottonii menggunakan pengukuran langsung pada 11 titik sampling tgl. 11 Juli 2013 di perairan pantai Amal dan Mamburungan, dan P. Sadau dengan parameter suhu, salinitas, kecerahan, turbiditas, kimia keasaman, nitrat, fosfat, kalium. Hasil penelitian menunjukkan faktor lingkungan sangat dipengaruhi variabilitas ENSO dan Musim. Perairan timur Tarakan memiliki tingkat kesesuaian lebih tinggi daripada bagian barat. Arus Lintas Indonesia mempengaruhi transfer massa air dari kolam panas Pasifik Barat memasuki perairan Tarakan. Pada perioda El Nino dan musim Timur perairan Tarakan timur memiliki tingkat kesesuaian tinggi dan selama La Nina dan Musim Barat tingkat kesesuaian tinggi berpindah ke utara perairan Tarakan. Analisis kesesuaian lahan budidaya dengan metoda scoring dan pembobotan menunjukkan perairan sekitar pantai Amal sampai selatan memiliki kesesuaian paling tinggi dan pantai Mamburungan dan P. Sadau dengan kesesuian sedang. Analisis tingkat kesesuaian di perairan Tarakan menggunakan data satelit inderaja memberikan informasi pada perioda El Nino berada di pantai Amal dan Tanjung Simaya, perioda La Nina di Tanjung Simaya dan Juata, perioda Normal di Tanjung Binalatung dan Simaya, Musim Barat di Tanjung Simaya dan Juata, dan Musim Timur di pantai Amal dan Tanjung Selayang.
\end{abstract}

Kata kunci: dinamika oseanografi, variabilitas ENSO dan musim, tingkat kekesuaian

\section{ABSTRACT}

Remote sensing oceanography of Aqua MODIS and altimetry have been applied to study environmental changes of sea surface temperature, chlorophyll-a, and surface current in the Tarakan water against ENSO and Monsoon variability in order to know dynamical oceanography during El Nino (December 2008, January-February 2009), La Nina (September-OctoberNovember 2010), and Neutral (May-June-July 2012), Northwest monsoon/NW (December, January, February during 2008, 2009, 2010, 2012), Southeast monsoon/SE (June, July, August during 2009, 2010, 2012). The suitability analysis of seaweed cultivation of Eucheuma cottonii is done using 11 sampling techniques on 11 July 2013 in the Amal and Mamburungan beaches and Sadau island with parameters of temperature, salinity, brightness, turbidity, acidity, nitrate, phosphate, and kalium. The results show that environmental changes of Tarakan water affected by ENSO and monsoons. The suitability rate is better in the eastern than western Tarakan water. The Indonesian throughflow plays important role in transferring water masses from warm pool western tropical Pacific entering northern and western Tarakan. Analysis of suitability rate using scoring and weighting methods indicates that water of Amal beach until southern part has the highest suitability rate and Mamburungan beach until Sadau island are moderate. The suitability rate using satellite oceanography implies potential areas for the development of seaweed cultivation of Eucheuma cottonii in the water of Amal beach and Cape Simaya during El Nino, Capes of Simaya and Juata during La Nina; Capes of Binalatung dan Simaya during Neutral;, Capes of Simayaand Juata during Northwest monsoon; and Amal beach and cape Selayang during Southeast monsoon.

\section{Keywords: dynamical oceanography, ENSO and monsoon variability, suitability rate}

\section{PENDAHULUAN}

Dewasa ini perkembangan teknologi satelit inderaja oseanografi berkembang sangat pesat. Perubahan kondisi oseanografi yang terjadi di suatu perairan dapat dipantau dengan cepat (resolusi waktu dalam harian) dan akurat (resolusi spasial dalam meter) hingga mencapai daerah terpencil yang sulit dijelajah melalui pengamatan langsung. Satelit Aqua MODIS dapat merekam informasi perubahan karakteristik yang terjadi di perairan Indonesia setiap pagi dan malam setiap hari. Satelit altimetri TOPEX/ POSEIDON dan yang terkini JASON 1 dan 2 dapat mengamati perubahan topografi muka air laut dan arus geostrofik yang terjadi di suatu perairan (Ducet et al., 2000, Traon et al., 1998)

Satelit inderaja oseanografi di atas dimanfaatkan untuk memantau perubahan kondisi lingkungan perairan Kota Tarakan yang disebabkan variabilitas ENSO dan musim dan pengaruhnya terhadap pengembangan budidaya rumput laut jenis Eucheuma cottonii. Pengukuran langsung parameter oseanografi di perairan pantai Tarakan juga digunakan untuk validasi dan analisis kesesuaian lokasi budidaya rumput laut. Makalah ini melakukan analisis matrik kesesuaian dengan masukan data satelit inderaja suhu permukaan laut, klorofil-a, dan arus permukaan 
untuk mendapatkan informasi lokasi potensial kesusaian lahan untuk pengembangan budidaya rumput laut Eucheuma cottonii berdasarkan faktor pembatas variabilitas kondisi oseanografi perairan Tarakan yang dipengaruhi perubahan ENSO dan musim di perairan Tarakan.

Budidaya rumput laut Eucheuma cottonii di perairan Tarakan sudah berlangsung sejak Tahun 2011, pada mulanya hanya sebagai usaha sampingan ketika berhenti melaut. Namun ternyata usaha ini sangat berkembang pesat sehingga terjadi perubahan paradigma masyarakat usaha budidaya rumput laut yang semula merupakan usaha samping saat ini sudah menjadi usaha utama. Hanya saja pengembangan budidaya rumput laut tersebut belum ada aturan hukum yang mengatur kegiatan budidaya tersebut. Memenuhi amanat dari Undang Undang No.1 Tahun 2014 yang merupakan perubahan dari Undang Undang No. 272007 tentang Pengelolaan Wilayah Pesisir dan Pulau pulau Kecil, maka penelitian ini dilakukan untuk mengetahui tingkat kesesuai lahan budidaya rumput laut Euchema cottonii dengan pembatas perubahan ENSO dan Musim

\section{METODE PENELITIAN}

\section{Lokasi dan Waktu Penelitian}

Penelitian dilakukan di perairan Tarakan dengan mengambil batas wilayah geografis $3.117^{\circ}-3.466^{\circ}$ Lintang Utara dan $117.425^{\circ}$ - $117.782^{\circ}$ Bujur Timur. Beberapa parameter lingkungan yang diukur langsung (in situ) mencakup kondisi fisika, kimia dan biologi oseanografi yang berpengaruh terhadap kualitas rumput laut Eucheuma cottonii. Pemilihan lokasi untuk pengambilan beberapa sampel dilakukan di 11 stasiun pengamatanlyang ada di perairan Tarakan. Dalam penelitian ini lokasi untuk pengukuran dan pengambilan sampel adalah Pantai Amal, Mamburungan dan Pulau Sadau. Lokasi dan stasiun sampling disajikan pada Gambar 1.

Kondisi batimetri bawah permukaan perairan Tarakan ditampilkan pada Gambar 2. Batimetri perairan Tarakan secara umum bervariasi namun cukup dangkal lebih kecil $15 \mathrm{~m}$ di sekitar perairan pantai P. Tarakan, kecuali di bagian selatan yang memiliki kedalaman lebih besar dari $15 \mathrm{~m}$. Dengan demikian perairan pantai Tarakan secara umum memiliki potensial pengembangan budidaya rumput laut.

Pengambilan data satelit inderaja oseanografi dilakukan selama Tahun 2008, 2009, 2010 dan 2012 untuk citra satelit Aqua MODIS dan altimetry. sedangkan untuk pengambilan data langsung di lapangan (in situ) dilakukan pada Tanggal 11 Juli 2013.

Variabilitas ENSO ditinjau pada kejadian EI Nino (diwakili pada 3 bulan puncak, yaitu: Desember 2008, Januari dan Februari 2009); La Nina (diwakili pada 3 bulan puncak, yaitu: September 2010, Oktober 2010 dan November 2010); dan Normal (diwakili pada 3 bulan puncak, yaitu: Mei 2012, Juni 2012, dan Juli 2012), sedangkan Musim Barat diwakili pada 3 bulan puncak, yaitu: Desember, Januari dan Februari selama rentang pengamatan 2008, 2009, 2010, dan 2012 dan Musim Timur diwakili pada 3 bulan puncak, yaitu: Juni, Juli dan Agustus selama rentang pengamatan, 2009, 2010, dan 2012.

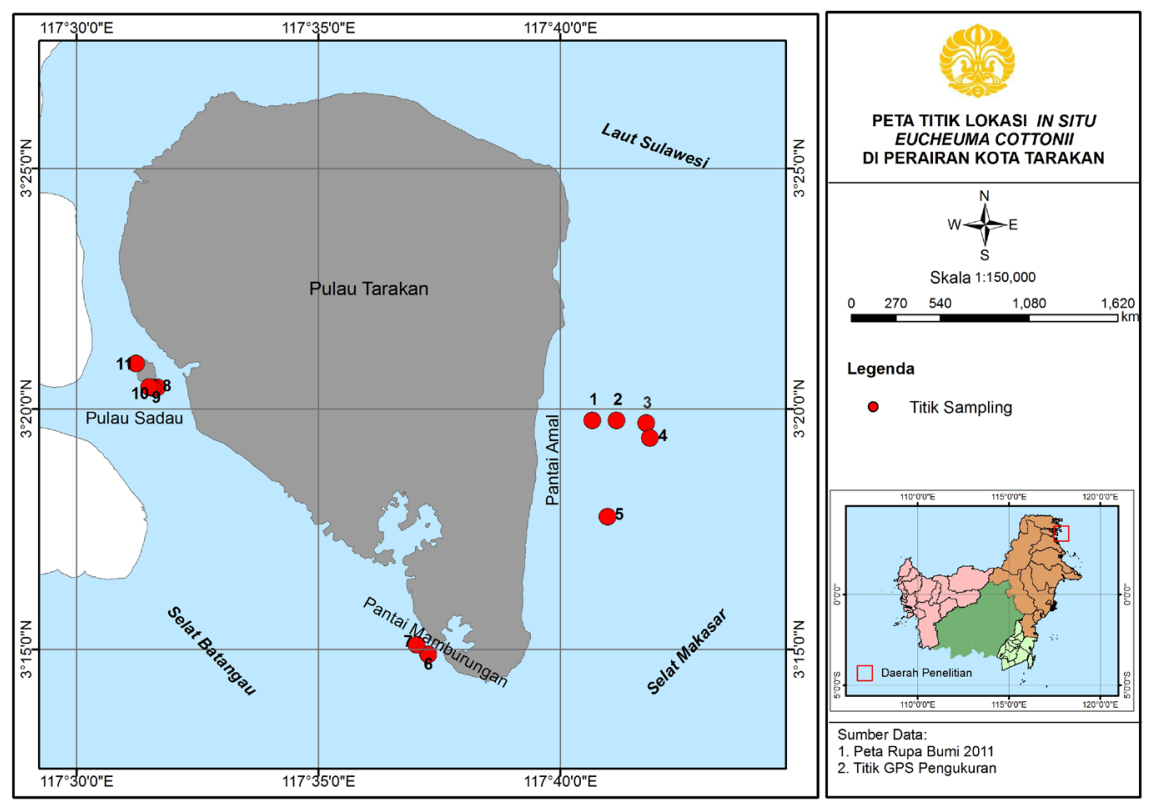

Gambar 1. Studi area penelitian di perairan Tarakan dan lokasi 11 titik sampling di pantai Amal, Mamburungan, dan P. Sadau 


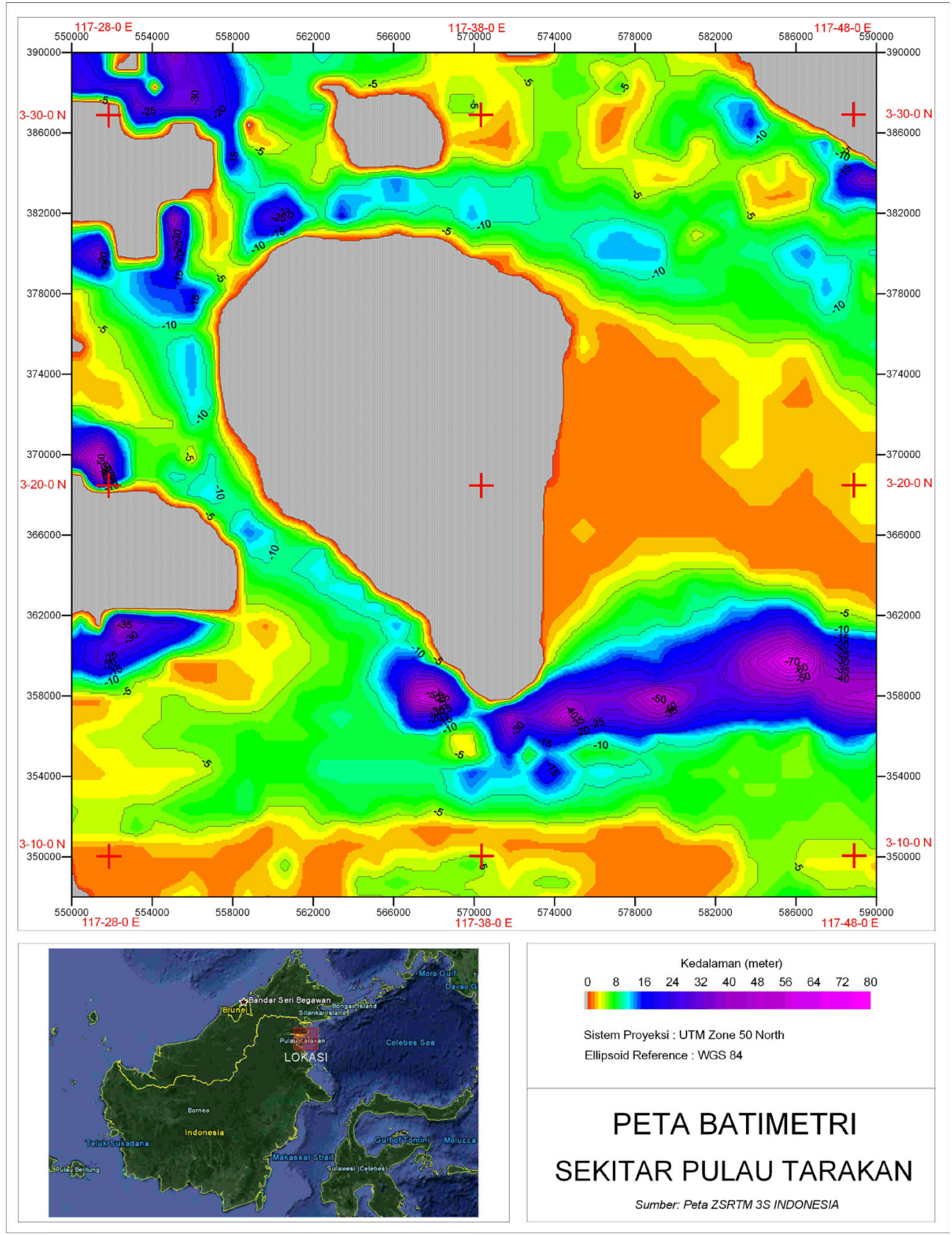

Gambar 2.

Peta batimetri area penelitian di perairan Tarakan.

Untuk acuan periodisasi ENSO, digunakan indek ONI (Oceanic Nino Index) karena perairan Tarakan berdekatan dengan lokasi terjadinya ENSO di perairan ekuator Pasifik. Gambar 3 adalah indek ONI selama perioda pengamatan ENSO dari 2008 s/d 2013. ONI positif $>0.5$ didefinisikan sebagai perioda EI Nino, dan ONI negatif $>-0.5$ didefiniskan sebagai perioda La Nina, sedangkan nilai diantaranya didefinisikan sebagai perioda normal.

Analisis sampel air laut yang diperoleh dari pengukuran lapangan dianalisis di Laboratorium Proling Institut Pertanian Bogor (IPB), sedangkan untuk pemrosesan data citra satelit dilakukan di NEONET (Nusantara Earth Observation Network) -
Badan Pengkajian dan Penerapan Teknologi.

\section{Pengolahan Data Satelit Inderaja dan Pengukuran Langsung}

Data citra satelit inderaja yang digunakan di perairan Tarakan adalah data yang bebas dari tutupan awan dan data dapat diolah pada kanal yang diperlukan. Data yang digunakan adalah citra Aqua MODIS level 1 dan level 3. Level 1 merupakan citra harian yang merupakan data mentah, yang digunakan adalah data level 1B yang merupakan Calibrated Radiances dan Geolocation, sedangkan level 3 merupakan data Aqua MODIS komposit bulanan klorofil-a dan suhu permukaan laut. 


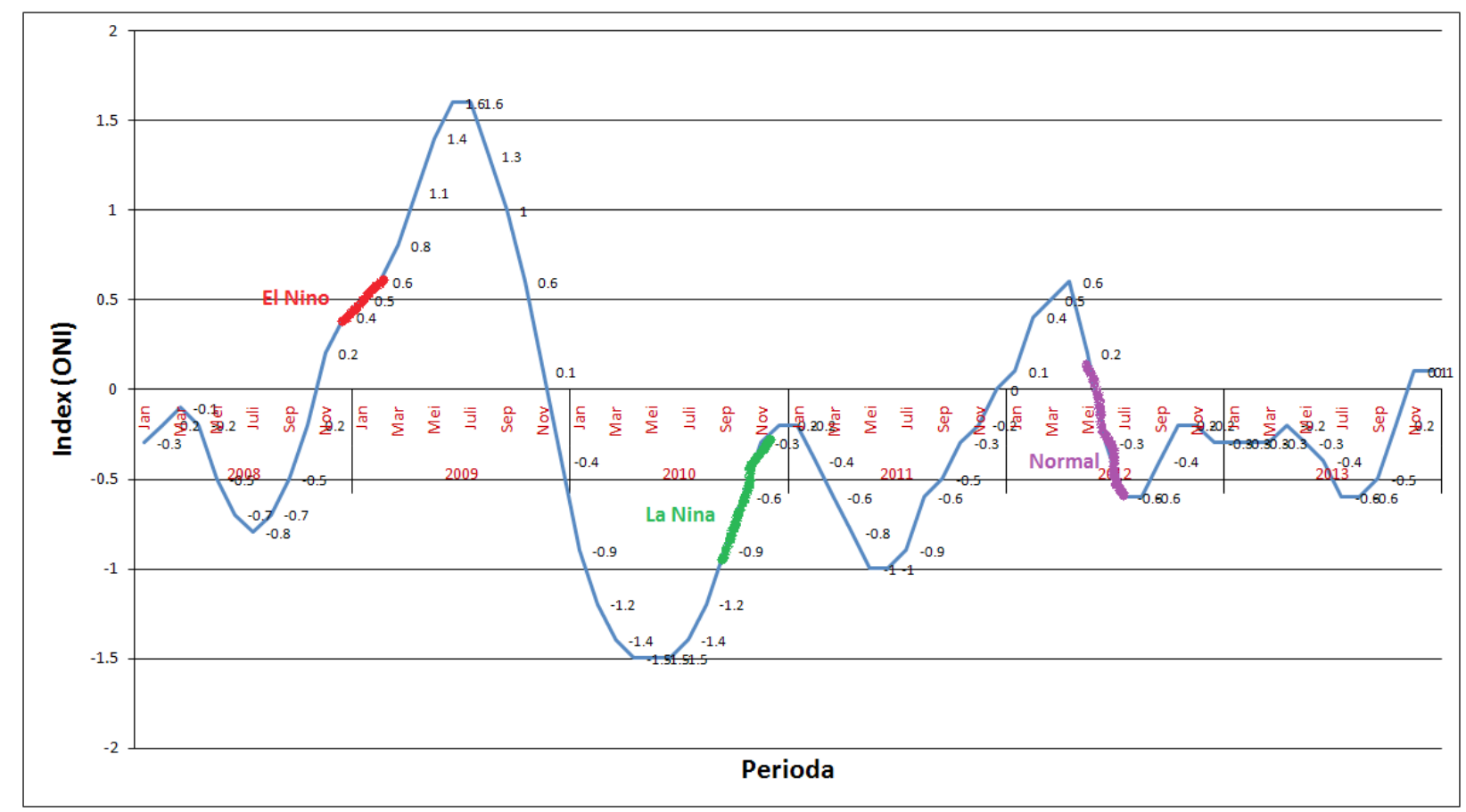

Sumber : http://www.cpc.noaa.gov/products/analysis_monitoring/ensostuff/ONI_change.shtml

Gambar 3. Grafik Indek ONI (Oceanic Nino Index) selama 2008 - 2013.

Pengumpulan data satelit altimetri dilakukan dengan mengunduh langsung melalui alamat laman AVISO CNES sebagai berikut: http://www.aviso. altimetry.fr/en/data/products/sea-surface-heightproducts.html. Data arus yang diperoleh merupakan integrasi dari empat (4) satelit altimetri JASON 1 dan JASON 2, Envisat, dan Cryosat 2.

\section{Analis Kesesuaian Lokasi Budidaya Rumput Laut Euchema cottonii}

Rumput laut jenis Euchema cottonii tergolong dalam jenis Rhodophyceae atau ganggang merah yang merupakan jenis rumput laut yang paling banyak dibudidayakan di perairan Indonesia, karena memiliki nilai ekonomis yang tinggi dan memiliki peran penting dalam meningkatkan produksi perikanan untuk pemenuhan pangan dan gizi serta untuk memenuhi pasar dalam dan luar negeri (Anggadiredja, et al. 2006).

Penyusunan matrik kesesuaian dilakukan dengan menggunakan kriteria-kriteria kesesuaian untuk kegiatan budidaya rumput laut. Kriteria kesesuaian disusun berdasarkan parameter biofisik yang relevan dengan kegiatan budidaya rumput laut dan dibuat dengan mengacu pata matrik kriteria kesesuaian dari berbagai studi pustaka yaitu: Kepmen No. 51/MENKLH/2004; Ariyati, et al. 2007; Septian 20142003.

Menurut Anggadireja, et al. (2006), beberapa faktor keberhasilan yang perlu diperhatikan dalam budidaya rumput laut selain bibit yang baik, metode, cara pemeliharaan, perlakuan pemanenan dan pasca panen, adalah pemilihan lokasi yang memenuhi persyaratan bagi jenis rumput laut yang dibudidayakan. Dengan demikian, perlu dilakukan pemetaan analisis kesesuaian lokasi sebelum dilakukan kegiatan budidaya. Pada penelitian ini, analisis kesesuaian lahan budidaya rumput laut dilakukan dalam 4 tahap, yaitu:

1. Penyusunan matriks kesesuaian lahan budidaya rumput laut,

2. Pembobotan dan pengharkatan (scoring),

3. Analisis proximity (pendekatan), yaitu membuat buffer berupa zona penyangga di sekeliling feature (informasi) dari coverage (tematik) input (titik dan garis) untuk membuat suatu coverage baru, dan

4. Analisis overlay (tumpang susun), yaitu proses penampakan coverage, dilakukan untuk menganalisis dan mengidentifikasi hubungan spasial antara feature-feature dari coverage.

Pada penelitian ini proses analisis dilakukan dengan menggunakan perangkat lunak software Arcmap 9. Kriteria kesesuaian lahan rumput laut untuk jenis Eucheuma cottonii adalah seperti yang ditunjukkan pada Tabel 1. 
Tabel 1.

Kriteria kesesuaian lahan untuk budidaya rumput laut

\begin{tabular}{|c|c|c|c|}
\hline Parameter/Kriteria & Class/Kelas & Skor & Bobot \\
\hline Kecepatan Arus (cm/dt) & $\begin{array}{l}20-40 \\
10-20 \text { atau } 40-50 \\
<10 \text { atau }>50\end{array}$ & $\begin{array}{l}3 \\
2 \\
1\end{array}$ & 3 \\
\hline Kecerahan (m) & $\begin{array}{l}>5 \\
3-5 \\
<3\end{array}$ & $\begin{array}{l}3 \\
2 \\
1\end{array}$ & 3 \\
\hline Suhu $\left({ }^{\circ} \mathrm{C}\right)$ & $\begin{array}{l}27-30 \\
25-<27 \text { atau }>30-32 \\
<25 \text { atau }>37\end{array}$ & $\begin{array}{l}3 \\
2 \\
1\end{array}$ & 1 \\
\hline $\mathrm{pH}$ & $\begin{array}{l}7-8,5 \\
6,5-<7 \text { atau }>8,5-9,5 \\
<6,5 \text { atau }>9,5\end{array}$ & $\begin{array}{l}3 \\
2 \\
1\end{array}$ & 1 \\
\hline Salinitas (\%o) & $\begin{array}{l}29-33 \\
25-<29 \text { atau }>33-37 \\
<25 \text { atau }>37\end{array}$ & $\begin{array}{l}3 \\
2 \\
1\end{array}$ & 1 \\
\hline Kedalaman (m) & $\begin{array}{l}1-10 \\
11-15 \\
<1 \text { atau }>15\end{array}$ & $\begin{array}{l}3 \\
2 \\
1\end{array}$ & 3 \\
\hline Nitrat (mg/L) & $\begin{array}{l}0,1-0,7 \\
0,01-<0,1 \\
<0,01\end{array}$ & $\begin{array}{l}3 \\
2 \\
1\end{array}$ & 3 \\
\hline Klorofil-a & $\begin{array}{l}3,5-10 \\
0,2-<3,5 \\
<0,2\end{array}$ & $\begin{array}{l}3 \\
2 \\
1\end{array}$ & 1 \\
\hline
\end{tabular}

\section{Pembobotan (Weighting) dan Pengharkatan (Scoring)}

Pemberian bobot didasari oleh tingkat kepentingan masing-masing parameter secara berurutan, mulai dari yang terpenting sampai yang kurang penting. Selain itu setiap parameter akan dibagi menjadi beberapa kelas yang diberi skor dan bobot berdasarkan tingkatan nilai kesesuaiannya. Parameter yang dapat memberikan pengaruh lebih kuat diberi bobot lebih tinggi daripada parameter yang lebih lemah pengaruhnya. Parameter kualitas air yang digunakan adalah suhu, salinitas, kecepatan arus, material dasar perairan, kecerahan, oksigen terlarut, nitrat, fosfat dan tinggi gelombang. Pengambilan data kualitas perairan dilakukan di 11 stasiun, sehingga pada hasil akhir akan diperoleh "nilai akhir" atau "matrik atribut" yang merupakan hasil perkalian antara bobot dengan skor kelas.

Setiap parameter, pemberian bobot, dan skor kelas ditentukan berdasarkan studi kepustakaan, dan justifikasi dari tenaga ahli yang berkompeten di bidang perikanan, baik secara tertulis maupun secara lisan.
Total nilai dari hasil perkalian nilai bobot parameter dengan skor tersebut selanjutnya dipakai untuk menentukan kelas kesesuaian lahan budidaya rumput laut berdasarkan karakteristik kualitas perairan dengan perhitungan sebagai berikut:

\section{$\mathbf{Y}=\boldsymbol{\Sigma}$ ai. $\mathbf{X n}$}

dengan: $Y=$ Nilai Akhir, ai $=$ Faktor pembobot, $\mathrm{Xn}=$ Nilai tingkat kesesuaian lahan

Interval kelas kesesuaian lahan diperoleh berdasarkan metode Equal Interval (Prahasta, 2002) guna membagi jangkauan nilai-nilai atribut ke dalam sub-sub jangkauan dengan ukuran yang sama. Perhitungannya adalah sebagai berikut:

$$
I=\left(\left(\sum \text { ai } \cdot X n\right) \cdot\left(\sum \text { ai } \cdot X n\right) \min \right) / \text { k }
$$

dengan: I = Interval kelas kesesuaian lahan, $\mathrm{k}$ = Jumlah kelas kesesuaian lahan yang diinginkan 


\section{HASIL DAN PEMBAHASAN}

\section{Dinamika Oseanografi Selama Perioda ENSO dan Perubahan Musim}

Nilai rerata dan standar deviasi Suhu Permukaan Laut (SPL), klorofil-a (kl-a) dan arus permukaan di perairan Tarakan selama perioda ENSO (EI Nino, La Nina, dan Normal) ditunjukkan masing-masing pada Gambar 4 dan 5. Perairan bagian timur Tarakan memiliki dinamika oseanografi yang baik untuk kesuburan perairan dengan SPL rendah dan daerah pertemuan (front) SPL dan kl-a yang rendah dan tinggi. Transport bersih (net transport) arus bergerak ke timur laut sebesar $6 \mathrm{~cm} / \mathrm{s}$ menunjukkan perairan Tarakan dalam waktu yang lama dipengaruhi arus dari selatan perairan Selat Makassar, dimana arus musim ditemukan sangat kuat selama musim barat dapat memasuki perairan Selat Makassar dan mencapai perairan Tarakan, meskipun nilainya kecil $6 \mathrm{~cm} / \mathrm{s}$.
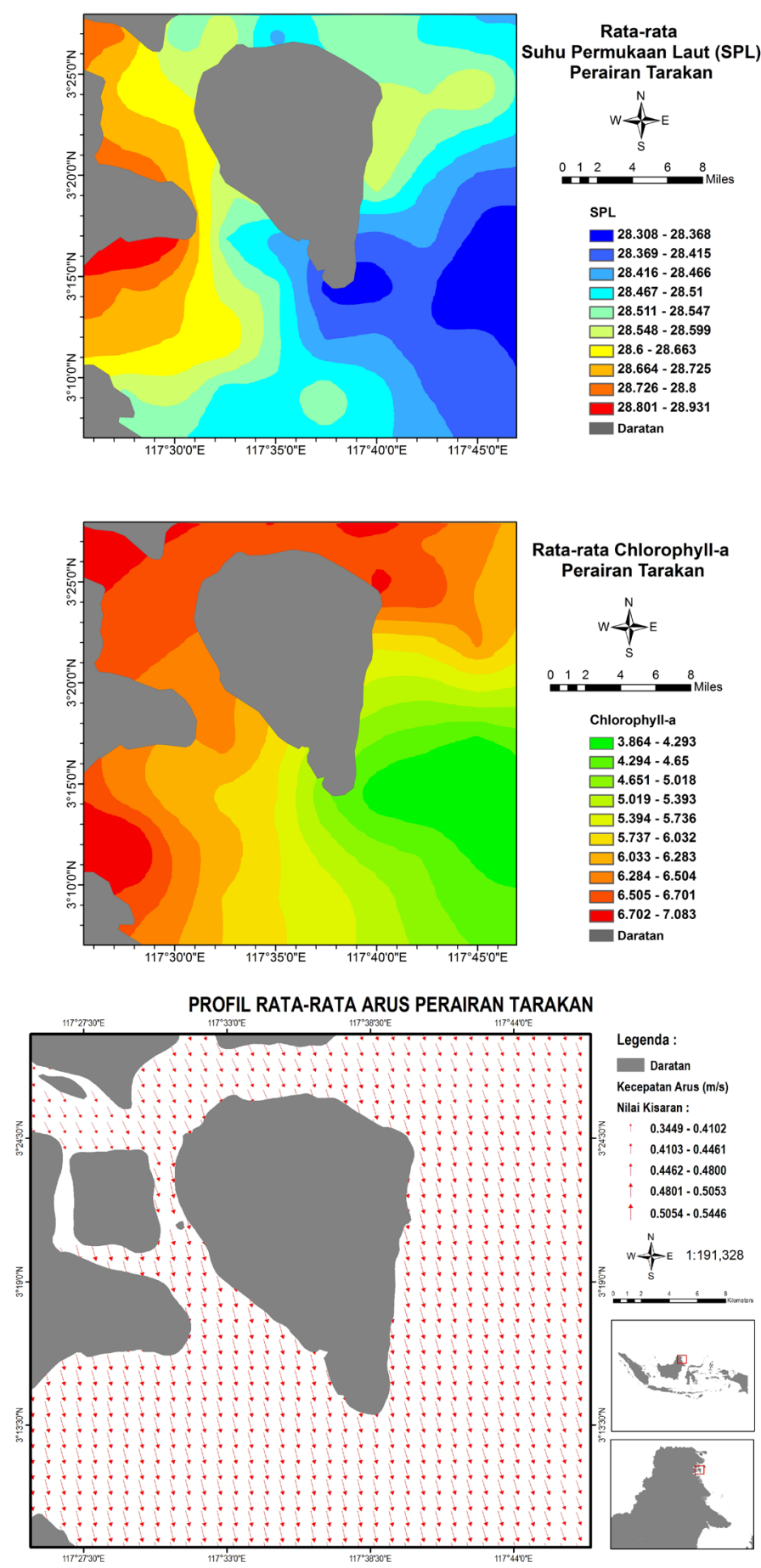

Gambar 4. Rerata suhu permukaan laut (SPL), klorofil-a, dan arus permukaan satelit inderaja. 


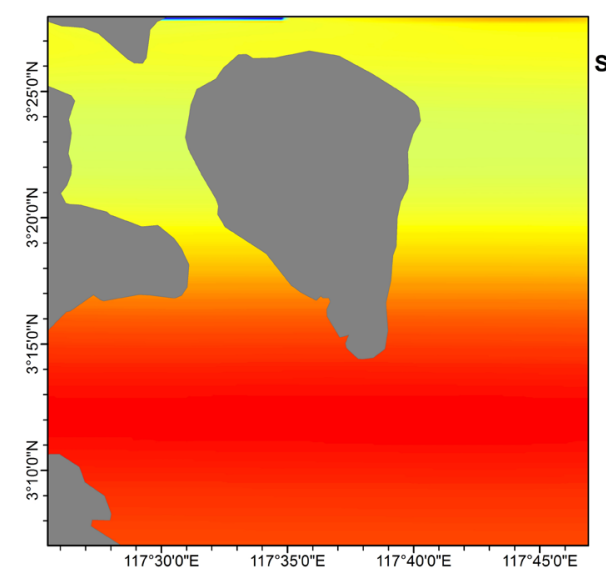

Standar Deviasi

Suhu Permukaan Laut (SPL)

Perairan Tarakan

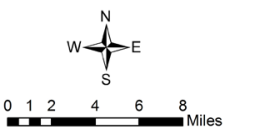

SPL
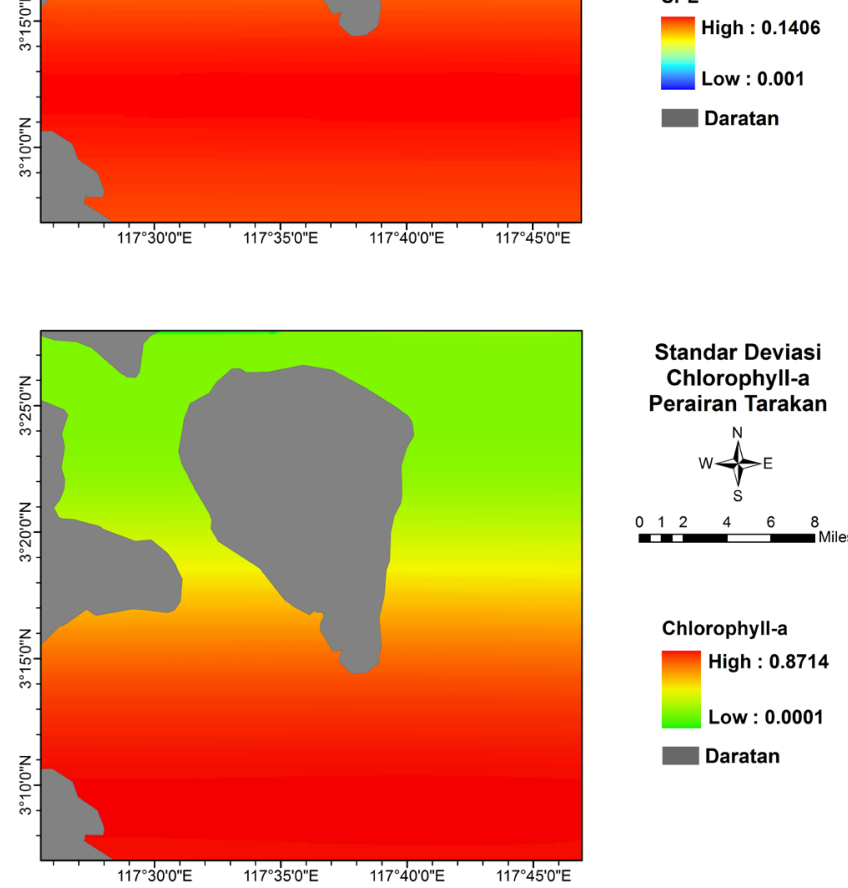

Standar Deviasi

Chlorophyll-a

Perairan Tarakan
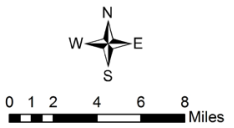

Chlorophyll-a

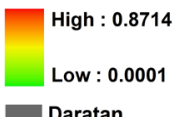

Daratan

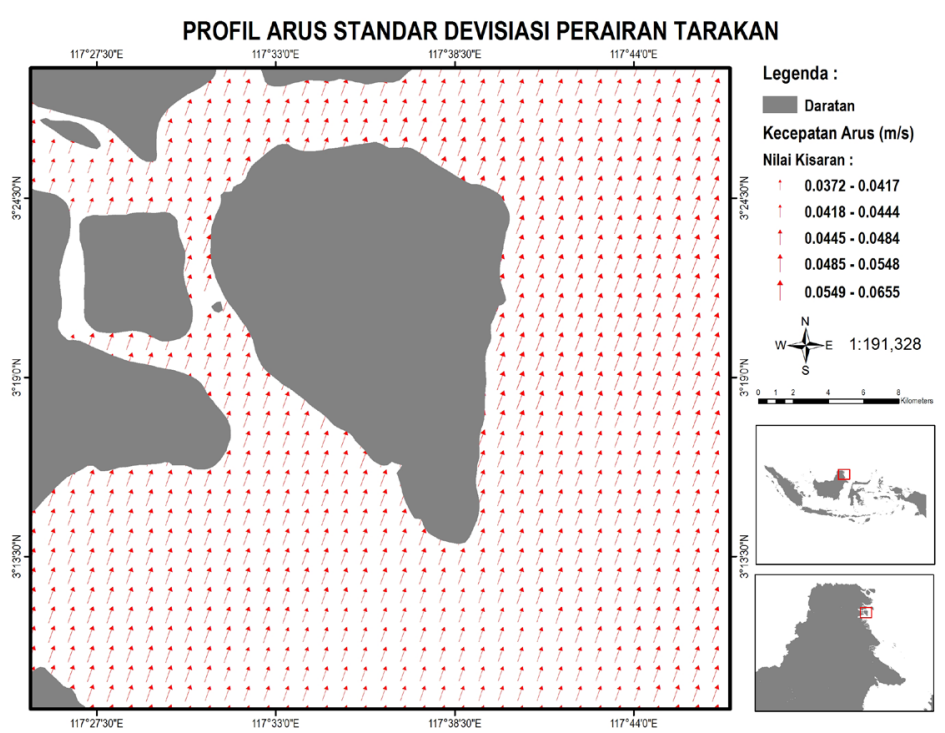

Gambar 5. Standar deviasi suhu permukaan laut (SPL), klorofil-a, dan arus permukaan satelit inderaja.

Perairan Tarakan sangat dipengaruhi suplai massa air dari kolam panas Pasifik Barat melalui laut Sulawesi di utara perairan Tarakan (Fine et al, 1994. Kondisi ini terlihat selama perioda El Nino 2009 dengan SPL relatif lebih rendah dengan rerata $28^{\circ} \mathrm{C}$ (Gambar 6A) , La Nina 2010 (Gambar 6B) dengan SPL relatif tinggi $29.5^{\circ} \mathrm{C}$ dan Normal 2012 (Gambar $6 \mathrm{C}$ ) dengan SPL sedang $29^{\circ} \mathrm{C}$. Kondisi SPL selama musim barat (Gambar 6D) dan timur (Gambar 6E) tidak terjadi kontras perbedaan yang mencolok, yaitu selama musim barat memiliki SPL dengan rerata $28.5^{\circ} \mathrm{C}$ dan musim timur dengan rerata $28.6^{\circ} \mathrm{C}$. SPL musim timur relatif lebih tinggi, karena mendapatkan suplai SPL hangat lebih besar dari kolam panas Pasifik barat. 

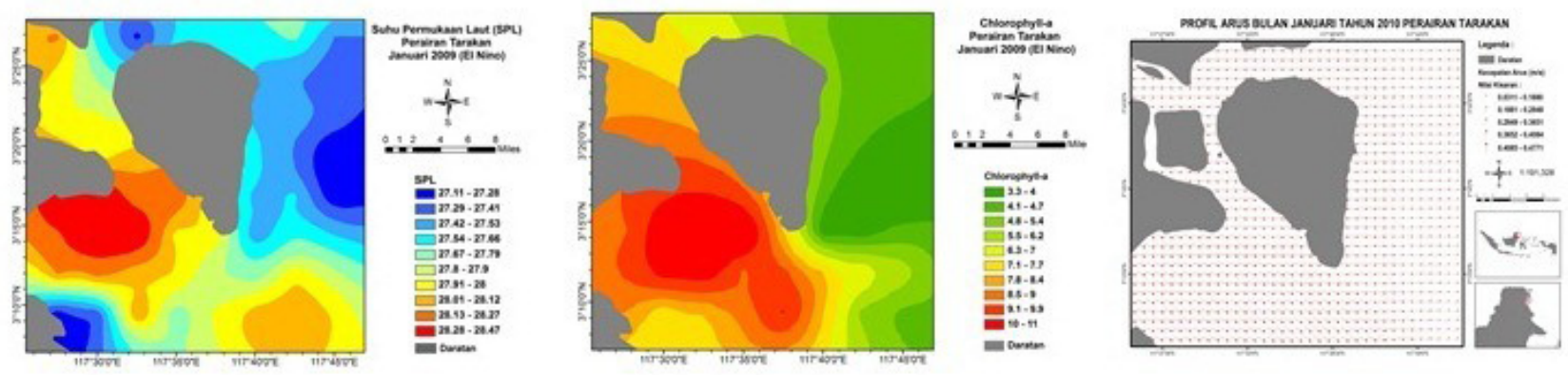

\section{A}
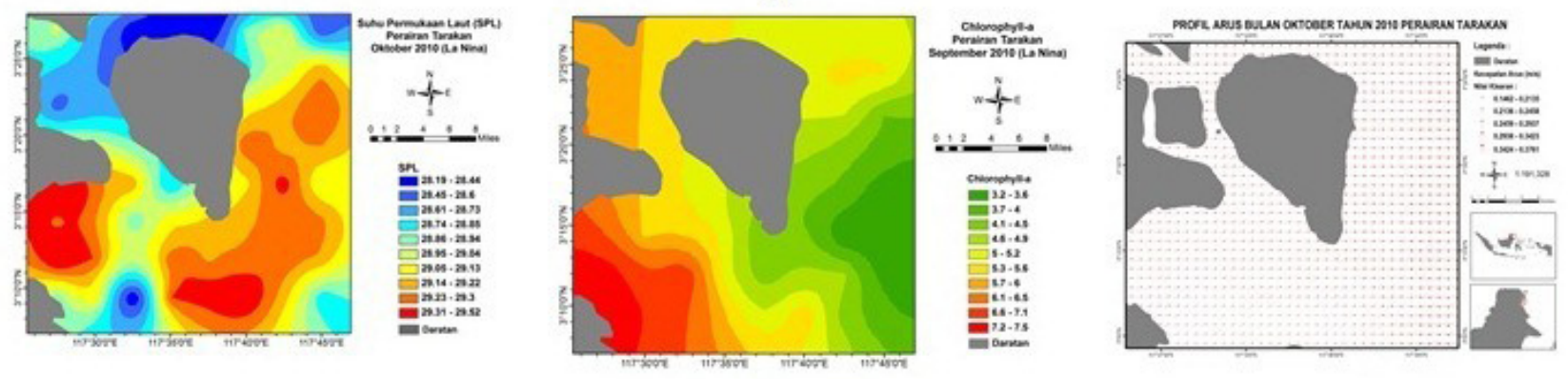

B
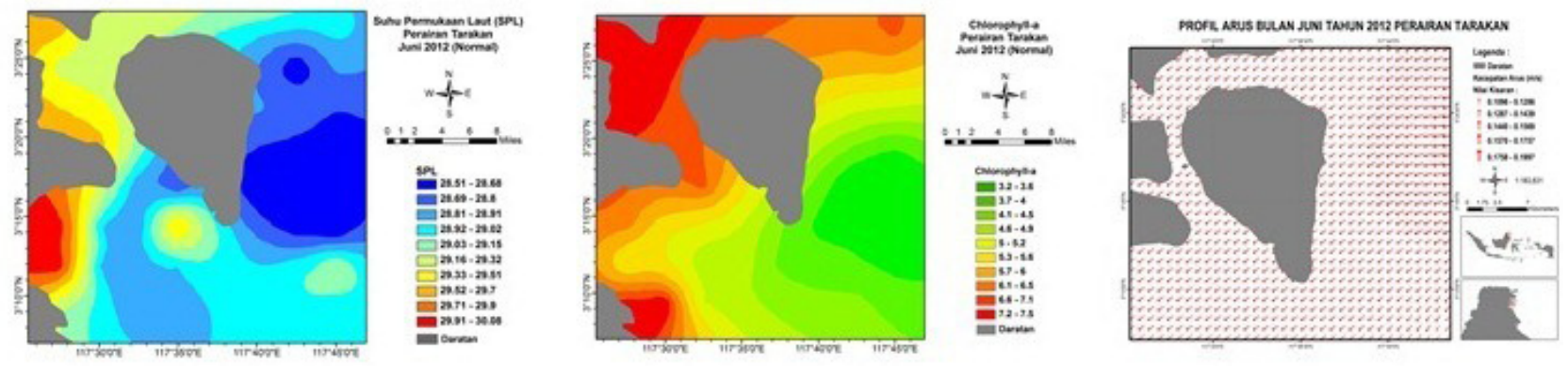

E
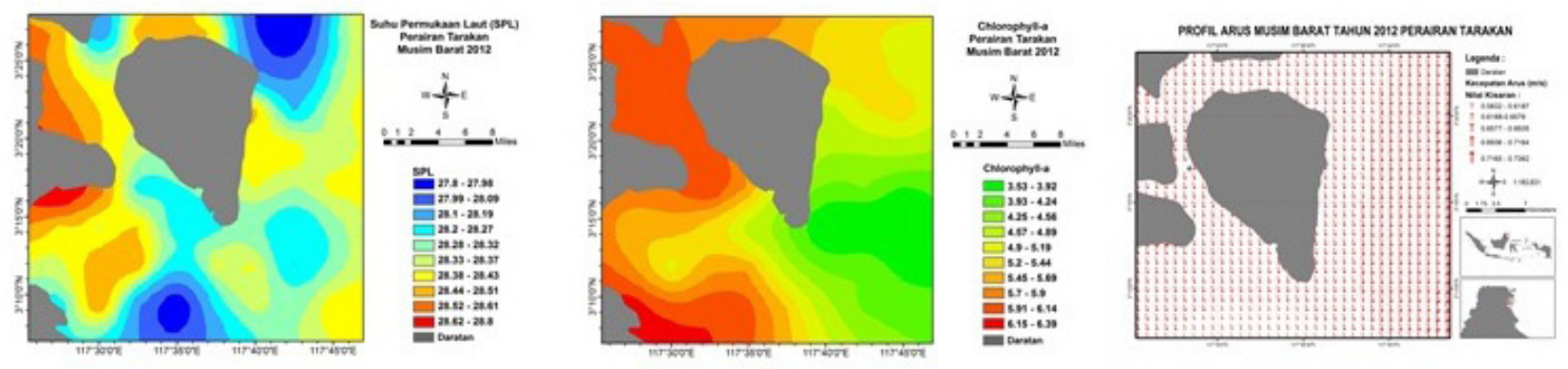

\section{D}
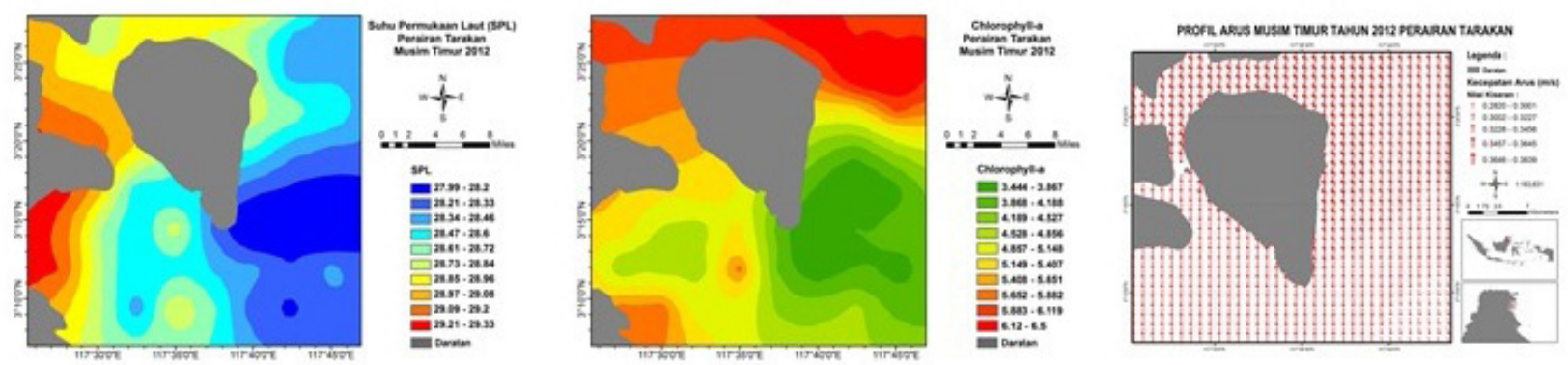

$\mathrm{E}$

Gambar 6. Suhu permukaan laut, klorofil-a, dan arus permukaan satelit inderaja selama (A) Perioda El Nino (B) Perioda La Nina (C) Perioda Normal (D) Musim Barat, dan (E) Musim Timur 
Dengan mengetahui dinamika oseanografi SPL ini dapat diketahui perairan timur Tarakan memiliki potensi kesuburan yang bagus selama terjadi fenomena El Nino. Pengaruh musim tidak terlihat perbedaan sangat kontras, namun musim timur menunjukkan kesuburan yang relatif lebih besar di perairan timur Tarakan.

Suplai massa air dari kolom panas Pasifik Barat di perairan Tarakan juga terlihat pada sebaran $\mathrm{kl}-\mathrm{a}$ relatif tinggi dalam kisaran $6-7 \mathrm{mg} / \mathrm{L}$ yang menandakan kesuburan dengan produktivitas primer tinggi berada di bagian timur laut sampai utara perairan Tarakan. Konsentrasi $\mathrm{kl}-\mathrm{a}$ relatif tinggi di wilayah tersebut terjadi pada perioda El Nino 2009 dan konsentrasi kl-a sedang selama perioda Normal 2012 serta lebih rendah selama perioda La Nina 2010. Musim timur dan barat menunjukkan konsentrasi kl-a relatif tinggi di wilayah tersebut dengan perluasan wilayah kesuburan sampai bagian timur perairan Tarakan terjadi pada musim timur.

Pergerakan dan besarnya arus permukaan di perairan Tarakan selama perioda El Nino 2009 menunjukkan pergerakan ke arah barat daya dan selatan dalam kisaran $45-60 \mathrm{~cm} / \mathrm{s}$. Arus permukaan ini merupakan arus lintas Indonesia (Arlindo) yang mengalir dari kolam Pasifik Barat melalui laut Sulawesi dan memasuki perairan Tarakan sebelum ke Selat Makassar. Pergerakan arus permukaan di perairan Tarakan dipengaruhi pergerakan arus yang datang dari selatan Selat Makassar dan bergerak ke arah timur laut dengan kisaran kecepatan $25-35 \mathrm{~cm} / \mathrm{s}$. Pergerakan arus ini melawan pergerakan Arlindo yang pada perioda normal ke arah selatan mendominasi perairan Tarakan dengan kisaran kecepatan $50-60$ $\mathrm{cm} / \mathrm{s}$.

Pergerakan arus permukaan selama musim barat dipengaruhi oleh kondisi regional ENSO, yaitu arus bergerak ke barat daya selama perioda EI Nino 2009 dan ke timur laut selama perioda La Nina 2010 dan ke selatan selama perioda Normal 2012 dengan masing-masing kecepatan 35,50 dan $60 \mathrm{~cm} / \mathrm{s}$. Kondisi pergerakan arus yang sama seperti di atas terjadi juga selama musim timur dengan intensitas kecepatan berbeda masing-masing 40, 45, dan $35 \mathrm{~cm} / \mathrm{s}$. Dengan demikian diketahui dinamika arus di perairan Tarakan dipengaruhi Arlindo selama perioda El Nino dan Normal. Arlindo tidak berpengaruh terhadap dinamika arus di perairan Tarakan selama perioda La Nina
2010. Kecepatan arus pada musim barat relatif lebih tinggi daripada musim timur. Hasil ini berbeda dengan pengukuran arus di kanal Labani Selat Makassar (Gordon et. al., 1998) yang melaporkan arus pada musim timur lebih besar daripada musim barat selama 2004 - 2006. Hal ini menunjukkan pengaruh arus yang datang dari selatan Selat Makassar, seperti arus musim, lebih dominan daripada Arlindo.

\section{Kesesuaian Lahan Budidaya Rumput Laut Eucheuma cottonii di Perairan Pantai Amal, Mamburungan dan Pulau Sadau}

Model Builder adalah suatu aplikasi yang ada di dalam software ArcGIS yang berguna untuk membuat, mengubah dan mengatur model, yaitu layer-layer dalam bentuk raster yang dapat dihubungkan satu sama lain dengan menggunakan perangkat geoprosesing (ESRI 2010).

Penelitian ini melakukan identifikasi zonasi kesesuaian perairan untuk lokasi budidaya rumput laut eucheuma cottonii. Model Builder digunakan dengan memasukkan rumusyang terdiridariperhitungan matriks kesesuaian parameter-parameter yang mempunyai bobot dan skoring. Analisis matriks kesesuaian untuk kegiatan budidaya laut diawali dengan penyusunan matriks kesesuaian. Data primer yang berupa data yang didapat dari lapangan digunakan dalam analisis matriks ini (Septian 2014, 2003). Perhitungan matriks kesesuaian dilakukan untuk pemberian skala penilaian. Skala penilaian adalah sebagai berikut:

1. S1 (Sangat Sesuai), apabila lahan tidak mempunyai pembatas yang berarti untuk mempertahankan tingkat pengelolaan yang diterapkan.

2. S2 (Sesuai), apabila lahan mempunyai pembatasagakberartiuntukmempertahankan tingkat pengelolaan yang harus diterapkan.

3. N (Kurang Sesuai), memiliki kelayakan yang rendah yaitu perairan memiliki faktor pembatas yang kuat untuk budidaya rumput laut, sehingga sangat berpengaruh terhadap kualitas perairan. Kondisi ini tidak memungkinkan untuk pengembangan budidaya rumput laut

Berdasarkan perhitungan dengan metode equal interval maka didapatkan interval kelas kesesuian

Tabel 2.

Tingkat kesesuaian lokasi budidaya Eucheuma cottonii

\begin{tabular}{llll}
\hline No & Total Skor & Tingkat Kesesuaian & Evaluasi \\
\hline 1. & $67,336-76$ & S1 & Sangat Sesuai \\
2. & $58,668-67,335$ & S2 & Sesuai \\
3. & $0-58,667$ & $\mathrm{~N}$ & Kurang Sesuai \\
\hline
\end{tabular}


PETA KESESUAIAN LAHAN BUDIDAYA RUMPUT LAUT DI PERAIRAN TARAKAN

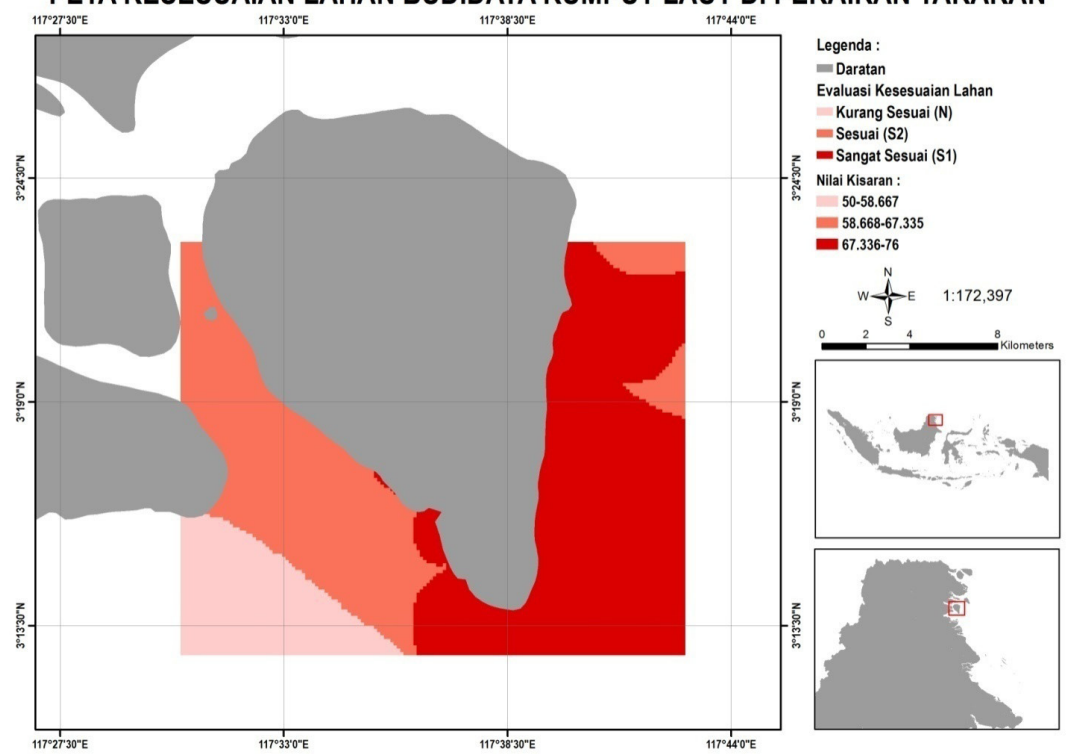

Gambar 7. Peta Kesesuaian (in situ) Lahan Budidaya Rumput Laut Eucheuma cottonii di Perairan Tarakan.

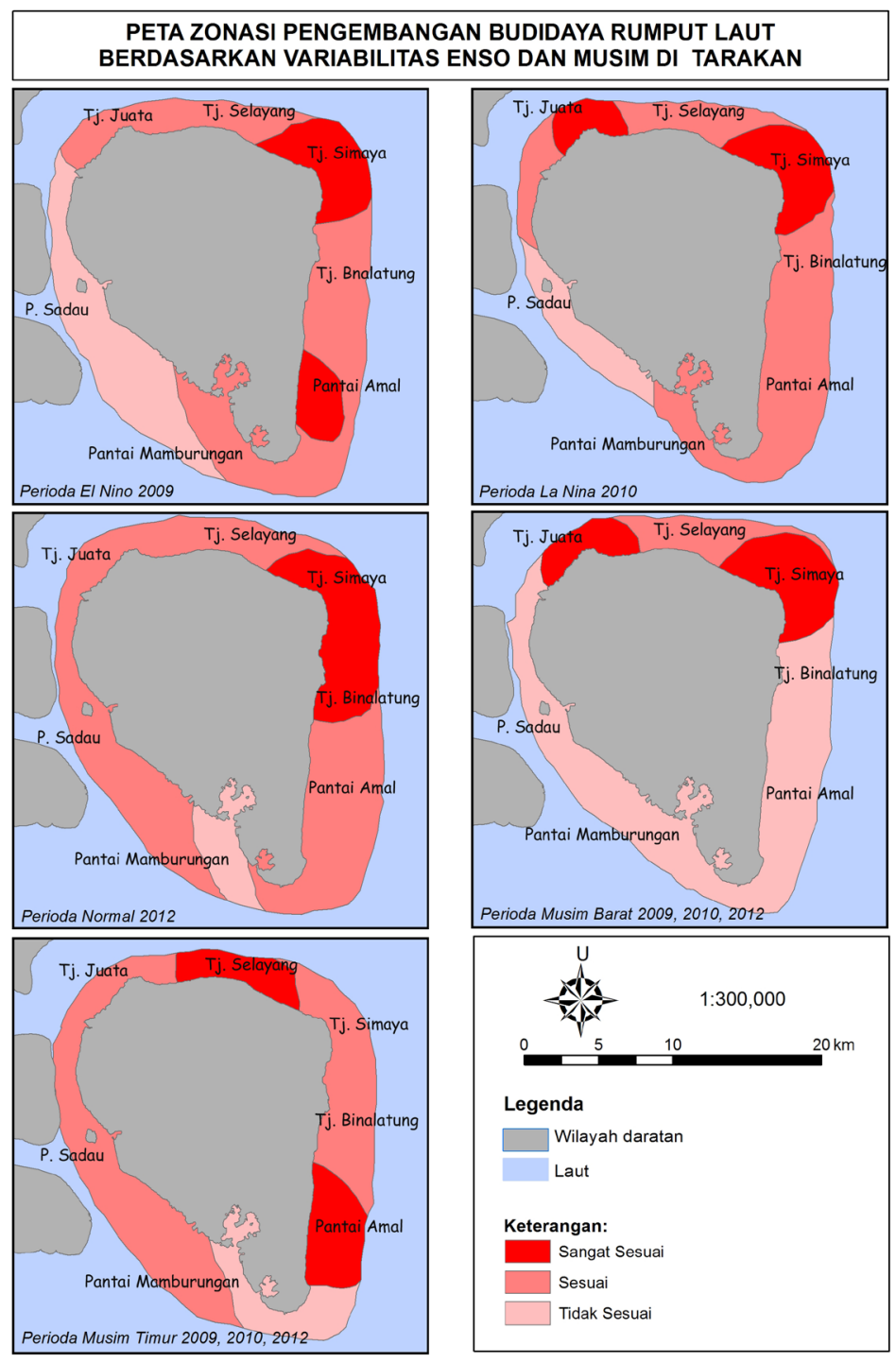

Gambar 8. Wilayah pengembangan budidaya rumput laut berdasarkan vaiabilitas ENSO dan Musim. 
seperti yang tercantum dalam Tabel 2.

Gambar 7 adalah peta kesesuaian lokasi budidaya rumput laut Eucheuma cottonii di perairan Tarakan. Perairan bagian timur - tenggra - selatan Tarakan memiliki tingkat kesesuaian paling tinggi untuk budidaya rumput laut, sedangkan bagian barat daya barat relatif lebih rendah.

Analisis kesesuaian ini sama dengan rekomendasi pengukuran langsung in situ parameter oseanografi (suhu, salinitas, kecerahan, turbiditas, keasaman, nitrat, fosfat, kalium dan klorofil) yang memberi indikasi perairan pantai Amal di bagian timur Tarakan memiliki rekomendasi paling tinggi/sesuai.

Analisis matrik tingkat kesesuaian perairan Tarakan menggunakan data satelit inderaja oseanografi untuk data SPL, kl-a, dan arus permukaan terhadap variabilitas ENSO dan Musim di perairan pantai Amal dan Mamburungan, dan P. Sadau menunjukkan kesamaan hasil menggunakan analisis kesesuaian lahan budidaya rumput laut Eucheuma cottonii dengan input data parameter fisika dan kimia oseanografi dari hasil pengukuran langsung pada Gambar 7, yaitu kesesuain lokasi budidaya dengan nilai sangat tinggi (sangat sesuai) berada di perairan pantai Amal dan sedang (sesuai) di perairan pantai Mamburungan dan P. Sadau.

Analisis matrik tingkat kesesuaian dilakukan juga untuk seluruh perairan Tarakan untuk mendapatkan informasi spasial lokasi yang memiliki kesesuaian tinggi, sedang, dan tidak sesuai berdasarkan variabilitas ENSO dan perubahan Musim dengan masukan data satelit inderaja suhu permukaan laut, klorofil-a dan arus permukaan sesuai dengan kriteria yang sudah ditentukan pada Tabel 1.

Gambar 8 adalah hasil analisis matrik tingkat kesesuaian perairan Tarakan untuk pengembangan budidaya rumput laut Eucheuma cottonii berdasarkan variabilitas ENSO dan Musim. Tingkat kesesuaian sangat tinggi pada perioda El Nino berada di perairan pantai Amal dan Tanjung Simaya; La Nina di Tanjung Simaya dan Juata; Normal di Tanjung Binalatung sampai Tanjung Simaya; Musim Barat di Tanjung Simaya, dan Juata; dan Musim Timur di pantai Amal dan Tanjung Selayang.

Analisis matrik tingkat kesesuaian ini menunjukkan lokasi kesesuaian perairan Tarakan sangat bergantung pada perubahan kondisi lingkungan perairan yang dipengaruhi variabilitas ENSO dan Musim. Tingkat kesesuaian perairan menentukan lokasi pengembangan budidaya rumput laut, sehingga informasi spasial dan temporal perubahan lokasi budidaya dapat dikembangkan untuk menentukan waktu tanam dan kebutuhan lainnya.

\section{KESIMPULAN}

Satelit inderaja oseanografi digunakan untuk mempelajari perubahan parameter lingkungan perairan Tarakan, yaitu: suhu, klorofil-a dan arus permukaan terhadap variabilitas ENSO (El Nino Southern Oscillation) dan perubahan Musim agar diperoleh pemahaman dinamika oseanografi selama perioda El Nino, La Nina dan Normal, dan Musim Barat dan Timur. Pemahaman ini diperlukan untuk mengetahui tingkat kesesuaian perairan Tarakan menurut waktu (temporal) dan ruang (spasial). Informasi faktor lingkungan perairan selanjutnya digunakan untuk menentukan lokasi budidaya rumput laut Eucheuma cottonii melalui analisis kesesuaian dengan mempertimbangkan parameter fisika dan kimia oseanografi yang diperoleh melalui pengukuran langsung (in situ) di perairan pantai Amal dan Mamburungan, dan P. Sadau.

Faktor lingkungan perairan sangat dipengaruhi variabilitas ENSO dan perubahan musim dan menjadi faktor pembatas tingkat kesesuaian lahan budidaya rumput laut Eucheuma cottonii. Dalam kaitan ini dinamika oseanografi yang memiliki kesuburan tinggi berkorelasi dengan tingkat kesesuaian tinggi. Perairan bagian timur Tarakan memiliki tingkat kesesuaian lebih tinggi daripada di bagian barat. Arus Lintas Indonesia (arlindo) mempengaruhi transfer massa air dari kolam panas Pasifik Barat memasuki perairan laut Sulawesi dan mencapai Tarakan (Gordon, 1986). Pada perioda El Nino dan Musim Timur perairan Tarakan bagian timur menunjukkan tingkat kesesuaian yang tinggi dan selama perioda La Nina dan Musim Barat tingkat kesesuaian perairan berpindah ke bagian utara perairan Tarakan.

Analisis kesesuaian lahan budidaya rumput laut Eucheuma cottonii dengan metoda scoring dan pembobotan menunjukkan perairan sekitar pantai Amal sampai ke selatan memiliki kesesuaian tinggi dan perairan pantai Mamburungan dan P. Sadau memiliki kesesuaian sedang.

Analisis matrik tingkat kesesuaian di perairan Tarakan menggunakan data satelit inderaja oseanografi memberikan informasi wilayah potensial pengembangan budidaya rumput laut pada perioda El Nino di perairan pantai Amal dan Tanjung Simaya, perioda La Nina di perairan Tanjung Simaya dan Juata, perioda Normal di Tanjung Binalatung dan Simaya, Musim Barat di perairan Tanjung Simaya dan Juata, dan Musim Timur di perairan pantai Amal dan Tanjung Selayang. 


\section{PERSANTUNAN}

Penulis mengucapkan terima kasih kepada Pimpinan dan staf Dinas Kelautan Perikanan Pemerintah Kota Tarakan untuk bantuannya dalam melakukan pengambilan data lapangan.

\section{DAFTAR PUSTAKA}

Amarullah. (2007). Pengelolaan Sumberdaya Perairan Teluk Tamiang Kabupaten Kota Baru Untuk Pengembangan Budidaya Rumput Laut (Eucheuma cottonii) Tesis, Bogor; Program Pascasarjana, Institut Pertanian Bogor, $136 \mathrm{hlm}$.

Anggadiredja, J., Zatnika, A., Purwoto, H., \& Istini, S. (2006). Rumput Laut, Pembudidayaan, Pengolahan dan Pemasaran Komoditas Perikanan Potensil. Penebar Swadaya Jakarta. $147 \mathrm{hlm}$.

Ariyati, R.W., Sya'rani, L. \& Arini, E. (2007). Analisis Kesesuaian Perairan Pulau Karimunjawa dan Pulau Kemujan Sebagai Lahan Budiaya Rumput Laut Menggunakan SIstem Informasi Geografi. Jurnal Pasir Laut, Vol 3, No.1, Juli 2007. 27-45

Aviso Satelillte Altimetrry Data: http://www.aviso. altimetry.fr/en/data/products/sea-surface-heightproducts.html, Diakses tanggal 20 Februari 2015

Ducet N, Le Traon PY, \& Reverdin, G. (2000). Global high-resolution mapping of Ocean Circulation from The Combination of T/P and ERS-1/2. Jurnal Geophys Res 105:19477-19498

ESRI. (2010). Model Builder-Executing Tools Tutoril. ESRI copyright

Fine R.A., Lukas, R., Bingham, F., Warnar, M. \& Gammon, R. (1994). The Westhern Equatorial Pacific: a water mass crossroads. J. Geophys. Res.,90, pp. 25063-25080

Gordon, A, R. (1996). Interocean exchange of thermocline water, J. Geophys. Res., 91, pp.50375046

Gordon, A. L., Susanto, R. D., Ffield, A. Huber, B. A., Pranowo, W. \& Wirasantosa, S. Makassar Strait Throughflow, 2004 to 2006,.., Geop Res Letts, Volume 35, Issue L24605, , (2008), 10.1029/2008GL036372

National Oceanic and Atmospheric Administration . n.d National Wheather Service Web: Climate Prediction Center. http://www.cpc.noaa.gov/ products/analysis_monitoring/ensostuff/ONI_ change.shtml, Diakses tanggal 27 Maret 2015

National Aeronotics and Space Admninistration n.d. MODIS Web : Components. http://modis.gsfc. nasa.gov/about/components.php. Diakses tanggal 20 Februari 2015

National Aeronotics and Space Admninistration n.d. MODIS Web : About. http://modis.gsfc.nasa. gov/about/components. php. Diakses tanggal 20 Februari 2015

Keputusan Menteri Negara Lingkungan Hidup Nomor 51 Tahun 2004 tentang Baku Mutu Air Laut.

Khasanah, U. (2013). Analisis Kesesuaian Perairan untuk Lokasi Budidaya Rumput Laut Eucheuma cottonii di Perairan Kecamatan Sajoanging, Kabupaten Wajo. Skripsi. Jurusan IImu Kelautan dan Perikanan. Universitas Hasanudin. Makasar

Le Traon PY, Nadal F. \& Ducet N. (1998). An Improved Mapping Method of Multisatellite Altimeter Data. Jurnal Atmos Ocean Technol 15: 522-533

Prahasta, Eddy. (2011). Tutorial ArcGis Dekstop untuk Bidang Geodesi dan Geomatika. Penerbit Informatika, Bandung.

Septian, I, Suherman, H. \& Harahap, S.A. (2014). Pemetaan Kesesuaian Perairan Untuk Budidaya Rumput Laut di Kepulauan Anabas Provinsi Kepulauan Riau. Jurnal Perikanan Kelauatan, Vol. V(2):240-247

Undang-undang Republik Indonesia Nomor 1 Tahun 2014, tentang Perubahan atas Undang-undang Nomor 27 Tahun 2007 Tentang Pengelolaan Wilayah Pesisir dan Pulau-pulau Kecil 